\title{
EXPLICIT MODELS FOR FOREIGN LANGUAGE STRATEGY LEARNING OF PRE- SERVICE TEACHERS AT UNIVERSITY LEVEL
}

\author{
Natalia Dmitrenko, Liudmyla Melnyk \\ Vinnytsia Mykhailo Kotsiubynskyi State Pedagogical University, Vinnytsia, Ukraine \\ nataliadmitrenko0302@gmail.com
}

\begin{abstract}
The purpose of the article is to prove theoretically and check experimentally the effectiveness of explicit models for language learning strategies based on the instructions in the process of professionally oriented English communication. The hypothesis of the research implies that the level of professional English communicative competence will increase in the case of combining such models as "top-down" and "bottom-up" while professionally oriented English communication. The study employed the mixed research design method as quantitative (Likert's scale, Bespalko's learning coefficient, Fisher's criterion) and qualitative (interpretation of questionnaire results) methods. The levels of explicit models using for language learning strategies are defined by the results of the conducted survey of 116 pre-service teachers of Vinnytsia Mykhailo Kotsiubynskyi State Pedagogical University. One of the conditions of experimental learning is a sequence of stages in the process of applying two explicit models for language strategy learning instruction "top-down" and "bottom-up" in the process of pre-service teachers' professionally oriented English communication. Findings. The results of the control test at the final step of the experiment have confirmed the effectiveness of two variants of explicit models for language strategy learning instruction in the process of professionally oriented English communication. The analysis of experimental training results has shown the formation of professionally oriented English communicative competence at the level B2, as well as a significant increase in the participants' knowledge, skills and abilities of foreign language learning strategies. Implications for research and practice. Combining "top-down" and "bottom-up" explicit models for language learning strategy instruction contributes to more effective assimilation and expansion of the repertoire of learning and communicative strategies and improves professionally oriented English communicative competence of pre-school teachers at university level.
\end{abstract}

Keywords: explicit model; implicit model; educational strategy; communicative strategy; professionally-oriented English communication.

\section{Introduction}

The application of learning strategies in the process of professionally oriented English communication plays an important role in increasing the level of professionally oriented English communicative competence. Among a great number of methods and ways to teach students how to use strategies, we point out the instructions which are introduced implicitly and explicitly in the content of a foreign language course on a systematical basis with the ability to share experience and improve a repertoire of strategies to perform a typical language task. The analysis of methodological studies highlights that one of the most effective ways of teaching a foreign language is integrating foreign language learning and language strategy learning. However, it is important to find out which implicit and explicit models support the development of professionally oriented English communicative competence.

\section{Literature Review}

Studies (Chamot \& O’Malley, 1987; Oxford \& Leaver, 1996) indicate that compared to isolated (separate from practice) lectures and workshops, integrated learning strategies are much more effective, which allows their incorporation into the curriculum to optimise student learning, as it involves the use of authentic communicative learning tasks and long-term use (Lai, 2013, p. 39). Grenfell \& Harris (1999), Oxford (1990) note that instructions for the application of strategies should be provided explicitly, integrating them into the practical course of learning a foreign language, as it allows students to practice strategies in authentic learning tasks, and teachers ought to direct the educational process to achieve educational goals (Sarada, 2019, p. 38).

In contrast to the implicit presentation of strategies, which does not provide students with special guidance on the purpose of learning (why you need to learn), explicit instructions cultivate a conscious attitude to the application of strategies, present the strategy, model its practical use, and help assess its effectiveness. Thus, informing students about how, when, and why strategies are used, allowing them to apply strategies in various educational tasks and to transfer the use of strategies to new contexts and tasks during training, which is extremely important in the conditions of professionally oriented English communication of pre-service teachers. 
The scientific and methodological literature presents various explicit models of mastering strategies based on instructions in the process of learning a foreign language. The most notable are: Person \& Dole (1987), Oxford (1990), Chamot (2005), Cohen (2000), Grenfell \& Harris (1999) and others.

Oxford's Strategy Training Model (STM) (Oxford, 1990) has a step-by-step application procedure and is flexible in terms of procedure, so each step can be changed or redesigned according to the tasks that contain different needs and intentions. The weakness of Oxford's model is that it is difficult to agree with the standard curriculum for learning a foreign language in higher education.

Chamot's Cognitive Academic Language Learning Approach Model (CALLA) (Chamot, 2005) is designed to develop the academic language skills of students with limited foreign language communication skills. Chamot's model integrates strategy learning into contextual and academic activities. The model is recursive, so teachers and students always have the opportunity to review previous learning stages and return to them. This model will be useful for those who study the language at different levels, which gives grounds to consider the possibility of its implementation in the context of learning a foreign language in higher education.

Cohen's Styles and Strategy-Based Instruction Model (SSBI) (Cohen, 2000) is student-centred and includes both explicit and implicit integration of strategies into the course content. Its author compares the teacher to a "change agent" who facilitates the learning of students and goes along with the student as a partner in the learning process. The presented model describes and recommends what the teacher should do in a foreign language class. It provides more flexibility for teachers to implement strategies implicitly or explicitly by adhering to the discipline curriculum.

Grenfell and Harris's Modern Language and Learning Strategies Model (MLLS) (Grenfell \& Harris, 1999) is divided into five parts: reading, listening, memorising, writing tests, communication strategies and involves following six steps of one cycle (awareness, modelling, general practice, action planning, focusing on practice, and evaluation). The peculiarity of this model is that it is linear and involves work in a cycle, which helps students to learn constantly about new strategies and make independent action plans for their individual language development.

Another linear cyclic model is presented by Macaro, Strategy Instruction Cycle Model (SIC) (Macaro, 2001), which includes the following steps of one cycle: activation of students' inner awareness; research of available strategies; modelling by a teacher or other students; combining strategies for a specific goal or task; application of support-based strategies; initial assessment by students; gradual elimination of support; teacher and student assessment; monitoring the application of strategies and rewarding efforts. Macaro's model is presented in three versions, which allows the teacher to choose the right option, depending on the characteristics of the group of students. For example, the first option: learning only metacognitive, social, and affective strategies; the second option: learning only cognitive strategies; the third option: learning one type of speech activity (reading or writing).

All the described models of mastering strategies are explicit and provide a "top-down" direction of learning (Gu, 2019, p. 25). According to researchers, the most common and one that can be a model of strategically oriented instructions is the model of Chamot (CALLA). The model has become a standard in the field of foreign language learning because it has been specifically designed to apply learning strategies in the process of learning a foreign language and contains an instructional package of materials that integrates content, language, and learning strategies. The proposed model is characterised by a significant shift of responsibility for learning from a teacher to students, and therefore, they are becoming more and more autonomous (Gu, 2019, p. 26).

As noted by Rubin et al.,(2007, p. 145), all "top-down" models have four main steps: increasing students' awareness and understanding of the strategies they already use; the teacher presents and models strategies in such a way that students increase awareness of their own cognitive and learning activities; increasing opportunities for speech practise to help students move towards autonomous use of strategies with a gradual decrease in support from the teacher; self-assessment of the effectiveness of the strategies and their transfer to new learning tasks. In order to implement these steps, researchers suggest using techniques and ways such as discussion aloud, questionnaires, creating focus groups, asking questions, filling out self-test sheets, keeping journals, diaries, portfolios, and reading special literature on the application of learning strategies (Dmitrenko et al, 2020).

In line with our study, the inverse model of learning "bottom-up" strategies is of interest, the advantage of which is the approach to the learning task and the relative ease of application in the educational process.

Butler's Strategic Content Learning Model (SCL) (Butler, 2002) is also a strategically oriented instructional "bottom-up" model, the basic premise of which is the assumption that if instruction focuses primarily on a prior direct explanation of strategy, then students may be inadvertently excluded from the problem-solving process, which is central to student self-regulation. In the educational process, the teacher 
does not start by choosing tasks, anticipating potential problems, and identifying strategies to teach students in a particular situation. Instead, the teacher works with students analysing content-oriented tasks and constructing potential strategies to help complete the task. The main function of the teacher is to support students' reflexive involvement in the cycles of self-regulated learning. Another distinctive feature of this model is the focus of explicit attention on how students reflexively and flexibly adapt learning strategies within recursive cycles of task analysis, application of strategies, and monitoring. In this interactive process of collaborative solution of the problem, the teacher immediately diagnoses potential problems in learning and attracts students to discuss the tasks, and in such a way, they are actively included in the choice, application, and evaluation of selected strategies and also are encouraged to talk about their decisions, and the acquisitions are fixed in the process of reflection.

The educational cycle of Butler's model (Butler, 2002) can be presented in the form of three stages: task analysis and metacognitive knowledge about academic work; individualised approaches to learning and metacognitive knowledge about strategies; self-monitoring, self-assessment, and positive self-perception. The teacher helps students to compare the results and criteria of the task, uses and interprets the feedback, reviews ineffective approaches, ensures the success of efforts related to the use of strategies, and identifies personal learning strategies for monitoring. Students formulate their understanding of how to use the strategy and continue to develop their learning strategies.

Thus, all of the above models have several common features that emphasise the key role of developing students' metacognitive understanding of the importance of applying strategies, which is supported by the teacher.

Nowadays, learning strategies used in the language learning process are studied by many language learning professionals, among them there are Alhaysony (2017); Alshammari (2020); Charoento (2017); Dawadi (2017); Griffiths \& Incecay (2016); Habók \& Magyar (2018); Habók et al., (2021); Kline (2015); Oxford, (2016); Pfenninger \& Singleton (2017); Platsidou \& Kantaridou (2014); Rao (2016). Several scientific studies (Anderson, 2005; Green \& Oxford, 1995; Griffiths, 2003; 2013; Lee, 2003; Naeimi \& Foo, 2015; O’Malley \& Chamot, 1990; Rahimi et al., 2008; Shawer, 2016; Taghinezhad et al., 2016; Thomson \& Mehring, 2016; Urlaub, 2012) have dealt with the interaction between learning strategies and students' knowledge. The need and importance of students mastering effective strategies for learning and using a foreign language are based on the following: mentally active students are more successful in learning: students who consciously organise and integrate new information into already stored in memory, have more cognitive connections that support comprehension and reproduction than those whose learning activity is limited to memorisation; strategies can be learned. More successful are students who have strategies and have the opportunity to apply them; strategies can be disseminated and transferred to other activities; learning a foreign language in an academic setting through strategies will be more effective because it has much in common with solving a problem situation in the native language (O'Malley \& Chamot, 1990, p. 196).

Thus, the analysis of scientific literature has shown that some explicit models for language strategy learning instruction are widely used in the process of English acquisition but their influence on the level of professionally oriented communicative competence of pre-service teachers at university level is not described.

The purpose of the article is an experimental verification of the effectiveness of application of explicit models for language strategy learning instruction of pre-service teachers in professionally oriented English communication at university level. The research hypothesis is that the level of professionally oriented English communicative competence of pre-service teachers will increase under the condition of a successful combination of "top-down" and "bottom-up" models in the process of professionally oriented English communication.

\section{Methods}

Research Design

The study employed the mixed research design method as quantitative and qualitative methods were used. The quantitative methods (Likert's scale, Bespalko's learning coefficient, Fisher's criterion) helped to identify the level of academic achievements and the level of explicit models using for language learning strategy instruction. The qualitative methods allowed us to interpret the results of the questionnaires. Descriptive statistics methods were used to analyse and systematise the data of the research.

\section{Participants}

The methodological experiment was held in 2017-2019 in Vinnytsia Mykhailo Kotsiubynskyi State Pedagogical University. The experimental training was carried out without a special selection of students, in 
usual conditions of the ordinary educational process within four semesters in the study of discipline "Foreign Language for Professional Communication (English)". 116 participants were divided into 4 subgroups of 2830 students, namely: experimental group 1 (EG1), experimental group 2 (EG2), experimental group 3 (EG3), experimental group 4 (EG4). In the process of experimental training, all students of experimental groups worked on the same educational materials, and were evaluated according to the same criteria. The participants were informed about the purpose, objectives, and the structure of the study and assured that the questionnaire would not affect the assessment of students' proficiency and their surnames would not be used in the study result reports. Participation in the study was voluntary.

\section{Instruments and Procedure}

The prerequisite for experimental training is the sequence of stages in the process of applying "topdown" and "bottom-up" explicit models for language strategy learning instruction.

The minimalism of the "top-down" model allows teachers to use it without special arrangement due to its simple implementation. Teachers, who are not familiar with strategic instructions, consider it useful and relevant to its simple and understandable instructions, at the same time, the model does not provide such teachers with confidence in the correct use of strategic instructions while working with students. However, the model of "bottom-up" does not require the theoretical training of a teacher in self-regulation and learning strategies but requires practical experience and flexibility in contextualisation, as well as an individual approach to accomplishing each task and setting up the necessary background knowledge in accordance with the capabilities and level of knowledge of the students. It has been determined that in the conditions of experimental training of the group EG1 and EG2 will be taught by the model "top-down" (variant 1), and groups of EG3 and EG4 according to the "bottom-up" model (variant 2).

In the first option, the teacher provided an explanation about the educational strategies that he planned to apply for a class or a familiar strategy to students. At the end, self-evaluation letters were used, compiled based on an adapted Cohen's questionnaire "Using Language Strategies" (Cohen, 2006), which were distributed according to various types of communicative activities. The main stages of the first (recursive, "top-down") variant are:

1) Preparation: a teacher defines the current student training strategies for already familiar types of tasks, in particular: updating of reference knowledge, preliminary review of the key dictionary and concepts that will be introduced to the class;

2) Presentation: a teacher models, explains a new strategy; asks students whether they have ever used it and how this happened, for example, a strategy of selective attention, self-control, substantiation of conclusions, elaboration, imagery, summation, and more;

3) Practice: students work out a new strategy; teacher encourages further use of the strategy in practice by applying it to make its statement, planning the development of an oral or written report or classification of concepts;

4) Self-evaluation: students evaluate their educational strategy immediately after practice, determining the effectiveness of their learning by summing up or independent statement, in a group or individually;

5) Expansion of activity: students carry strategies for new tasks, combining strategies to groups (clusters), developing a repertoire of preferred strategies, integrating them into existing knowledge frameworks;

6) Assessment: a teacher assesses the use of students' learning strategies and their impact on the solving of educational problems.

Studying by the second (cyclic, "bottom-up") variant, EG3 and EG4 students chose themselves educational strategies to perform tasks, and the teacher in the analysis of the fulfilled task helped them to determine the correctness of the applied strategy, contributed to the search other options for its application or alternative methods of task execution. The main methodological stages of the model "bottom-up" (variant 2) are as follows:

1) Preparation: a teacher supports students in determining the basic issues that need to be found for a task;

2) Choice: a teacher contributes to the discussion in which students (analysing the requirements of the task, determine the criteria for its implementation, emphasise the usefulness of the analysed task, and determine their strategies for the analysis of the analysed problem);

3) Practice: students apply a chosen strategy. The teacher directs students to raise the tasks, reflection of the learning process, definition and evaluation of strategies, the identification of success and ineffective methods; 
4) Self-evaluation: students are comprehending and fixing personal strategies with their own words and continue to develop the skills of using strategies;

5) Expansion: students with their own words transfer their understanding of how to use the educational strategy, and continue to develop the necessary educational strategies of activity;

6) Assessment: a teacher helps students in comparison with the results and criteria for performing a task, uses and interprets feedback, reviews inefficient approaches, links success with efforts that are enforced with strategies, identifies personal training strategies for monitoring.

The following three steps were realised during the experimental training:

1. At the beginning of experimental training, diagnostic testing was carried out to detect an input level of the components of students' professionally oriented English communicative competence in the first two practical classes of the first semester, namely: 1) the level of formation of professionally oriented English competence in listening, oral speech, reading, and writing; 2) the level of explicit models using for language learning strategy instruction.

The diagnostic testing of academic achievements was carried out to identify the input level of first-year students' language proficiency. Following the European Recommendations on Language Education (Council of Europe, 2018), as well as a working curriculum of discipline "Foreign Language for Professional Communication (English)" of Vinnytsia Mykhailo Kotsiubynskyi State Pedagogical University, students have to master English at the level of B1. To check the level of formation of professionally oriented English communicative competence, a test based on the International Cambridge Test PET (Preliminary English Test) was created, the results of which correspond to the level B1 of the European scale (CEFR) and are coherent with the methodological recommendations for this international test. The test results are the average arithmetic sum of scores from four types of communicative activities (25\% for each type) and can be agreed with the levels of formation of professionally oriented English communicative competence in listening comprehension, oral speech, reading, and writing.

The levels of explicit models using for language learning strategy instruction in the process of professionally oriented English communication are determined by the results of an adapted version 7.0 of Oxford's questionnaire "Repertoire of Language Strategies" for foreigners studying English (Oxford, 1990).

Oxford's questionnaire "Repertoire of Language Strategies" contains six categories of strategies that cover the answers to fifty issues on a five-point Likert scale (5 - always use, 4 - usually use, 3 - use from time to time, 2 - usually do not use, 1 - never use), among which: strategies for effective memorisation (category A, 1-9 issues), strategies for using all mental processes (category B, 10-23 issues), compensation strategies (category C, 24-29 issues), strategy for organisation and evaluation of education (category D, 3038 issues), emotion management strategies (category E, 39-44 issues), training strategies in cooperation with others (category F, 45-50 issues ). The answers to each issue (from 1 to 5) in each category are added and divided into a total number of statements of the corresponding category to obtain mean values. According to Oxford's questionnaire, the high level of explicit models using for language learning strategy instruction encompasses the value of medium indicators 5.0-4.5 (always use) and 4.4-3.5 (usually use); the average level is within 3.4-2.5 (use from time to time) and 2.4-1.5 (usually do not use); the low level has a value of medium indicators 1.4-1.0 (never use).

2. At the end of the first module (the end of the second semester of discipline studying), an intermediate (mid-year) assessment was carried out to determine the level of formation of professionally oriented English communicative competence. The test of educational achievements of the intermediate assessment, similar to the input test before the experiment, was carried out in order to identify changes and trends in the development of professionally oriented English communicative competence in listening comprehension, oral speech, reading, and writing.

At the same time, an intermediate re-questioning of explicit models using for language learning strategy instruction in the process of professionally oriented English communication was carried out. According to the results of the questionnaire, it has been determined the level of learning strategies use. EG1 and EG2 students studying according to the "top-down" model have achieved essential results in mastering learning strategies. At the same time, students EG3 and EG4 demonstrated lower results in mastering language strategies. Consequently, it's been assumed that the level of language learning strategies can increase due to cross-learning, which involves changing the methodology. That is, in one experimental group (EG2), which studied in the first variant, introduce a model of "bottom-up", and in the experimental group of EG4, which studied in the second variant, introduce the "top-down" model during the second year (3-4 semester) of training. Such experimental training involves checking the assumption that students originally studied on the model "top-down" and expanded the repertoire of language learning strategies, require greater autonomy for their choice, namely its own choice of the necessary strategy, depending on the conditions of application. At 
the same time, students of EG4 need to strengthen knowledge in the form of advice on the task and the correctness of the application of strategies in the study of language, as students do not always have enough knowledge to adhere to the correctness and consistency of language learning strategies in the process of professionally oriented English communication.

Thus, it has been decided to change the variants of using language learning strategies in two experimental groups: in EG2 the "top-down" model has replaced "bottom-up", and in EG4 the model "bottom-up" has changed the model "top-down". EG1 and EG3 continued to study their pre-defined variants of explicit models (Table 1).

Table 1. Distribution of experimental groups according to the variants of explicit models

\begin{tabular}{|c|c|c|c|c|}
\hline Model & Semester 1 & Semester 2 & Semester 3 & Semester 4 \\
\hline Variant 1: & EG1 & EG1 & EG1 & EG1 \\
"top-down" & EG2 & EG2 & EG4 & EG4 \\
\hline Variant 2: & EG3 & EG3 & EG3 & EG3 \\
"bottom-up" & EG4 & EG4 & EG2 & EG2 \\
\hline
\end{tabular}

3. At the end of the fourth semester, an output testing was conducted. The verification of the level of professionally oriented English communicative competence was carried out by using the test of academic achievements based on the International Certificate of English (First Certificate of English), the results of which correspond to the level B2 of the European scale (CEFR) and methodological recommendations for conducting the above international test. At the same time, the questionnaire on the level of explicit models using for language learning strategy instruction in the process of professionally oriented English communication was conducted.

After conducting experimental training of professionally oriented English communication, students of experimental groups were asked to evaluate the introduced method of explicit models using for language strategy learning instruction of pre-service teachers in the process of professionally oriented English communication at the university level.

\section{Data Analysis}

The mean learning coefficients of academic achievements have been calculated according to Bespalko's formula: $K=Q: N$, where $Q$ is the number of obtained points, and $N$ is the maximum possible number of obtained points. The level of learning is considered satisfactory if the mean values are not lower than a sufficient level of learning - 0.7 (Bespalko, 1968).

The reliability of the received data was verified by the multifunctional statistical criterion - Fisher angular transformation $\left(\varphi^{*}\right)$, which is used to compare two samples by the frequency of the effect by transferring the percentage particles of the central angle (Fisher, 2017). For this purpose, the interest rates of students who have and who have no effect ("there is an effect" / "no effect") are determined, and the zero $\left(\mathrm{H}_{0}\right)$ and alternative $\left(\mathrm{H}_{1}\right)$ statistical hypotheses for each EG are formulated by comparing the results of the input and output experimental test results in each experimental group and the formulation of statistical hypotheses - about the absence of differences $\left(\mathrm{H}_{0}\right)$ and the significance of differences $\left(\mathrm{H}_{1}\right)$.

The empirical value $\varphi^{*}$ is calculated by the formula:

$$
\varphi^{*}=\left(\varphi_{1}-\varphi_{2}\right) \cdot \sqrt{\frac{n_{1} \cdot n_{2}}{n_{1}+n_{2}}}
$$

\section{Results}

The levels of explicit models using for language learning strategy instruction are determined by the results of the questionnaire, which based on a version 7.0 of Oxford's questionnaire "Repertoire of Language Strategies" for foreigners who learn English (Oxford, 1990). The results of questioning about the use of strategies in the mastering foreign language of the input, intermediate, and output assessment of experimental training are given in Table 2.

Table 2. Mean values of the level of explicit models using for language learning strategy instruction

\begin{tabular}{|l|l|c|c|c|c|}
\hline & \multicolumn{1}{|c|}{ Category } & $\begin{array}{c}\text { Number } \\
\text { of } \\
\text { students }\end{array}$ & $\begin{array}{c}\text { Mean values of } \\
\text { input assessment }\end{array}$ & $\begin{array}{c}\text { Mean values of } \\
\text { intermediate } \\
\text { assessment }\end{array}$ & $\begin{array}{c}\text { Mean values of } \\
\text { output } \\
\text { assessment }\end{array}$ \\
\hline A. & $\begin{array}{l}\text { Strategies for effective } \\
\text { memorisation }\end{array}$ & 116 & 2.94 & 3.15 & 3.45 \\
\hline
\end{tabular}




\begin{tabular}{|l|l|c|c|c|c|}
\hline B. & $\begin{array}{l}\text { Strategies for using all } \\
\text { mental processes }\end{array}$ & 116 & 2.92 & 3.17 & 3.43 \\
\hline C. & Compensatory strategies & 116 & 3.14 & 3.37 & 3.18 \\
\hline D. & $\begin{array}{l}\text { Strategies of } \\
\text { organisation and } \\
\text { evaluation of training }\end{array}$ & 116 & 3.05 & 2.89 & 3.59 \\
\hline E. & $\begin{array}{l}\text { Emotion management } \\
\text { strategies }\end{array}$ & 116 & 2.66 & 3.34 & 3.62 \\
\hline F. & $\begin{array}{l}\text { Student strategies in } \\
\text { cooperation with others }\end{array}$ & 116 & 3.16 & 3.18 & 3.48 \\
\hline & $\begin{array}{l}\text { The mean values of all } \\
\text { categories }\end{array}$ & 116 & 2.97 & & 3.23 \\
\hline
\end{tabular}

As can be seen from the results of the questionnaire (Table 1), the mastery of strategies of pre-service teachers in professionally oriented English communication at the beginning of experimental training has been developed at an average level. The ability to use emotion management strategies is the least developed. It is worth noting that only four students approached the average value of 4 in this category, which indicates that the skill level of this category is approaching the lower limit. That is, students do not know how or rarely use strategies for complacency, encouragement, self-analysis of their behaviour, do not apply for advice to a teacher or another person about their emotional state.

The highest averages have been recorded in the category of using strategies in cooperation with others. Among the answers to the statements of this category, the following are highlighted: in case something is unclear, try to ask the interlocutor to repeat what was said; speech practice with other students; attempt to ask questions in English; desire to learn about native speakers' cultures. At the same time, high scores are given to the request for help and the desire when there are mistakes, to be corrected by the teacher. That is, students believe that if a problem arises, it is better for them to ask the teacher for help than to look for ways to solve it on their own, and they prefer the teacher's control or mutual control, rather than self-control and selfassessment.

The results of the input test of academic achievements have shown that first-year students have a low level of language proficiency, which corresponds to the lower limit of level B1 towards $\mathrm{A} 2+$, and the results in the experimental groups have no significant deviations and are relatively homogeneous (Table 3).

Table 3. The results of input testing to determine the level of professionally oriented English communicative competence

\begin{tabular}{|c|c|c|c|c|c|c|c|c|c|c|c|}
\hline \multirow[t]{2}{*}{ № } & \multirow{2}{*}{$\begin{array}{c}\text { Type of communicative } \\
\text { activity }\end{array}$} & \multirow{2}{*}{$\begin{array}{c}\text { Total } \\
\text { number of } \\
\text { students }\end{array}$} & \multicolumn{3}{|c|}{ Input Test } & \multicolumn{3}{|c|}{ Intermediate Test } & \multicolumn{3}{|c|}{ Output Test } \\
\hline & & & $\frac{\bar{d}}{20}$ & 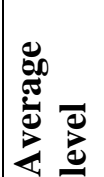 & $\frac{\bar{d}}{2}$ & 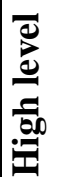 & 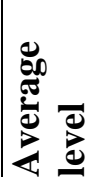 & $\frac{0}{0}$ & $\frac{\bar{d}}{20}$ & 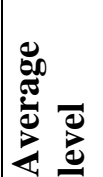 & $\frac{0}{0}$ \\
\hline 1. & Listening Comprehension & 116 & 4 & $4 \overline{2}$ & 70 & 10 & 70 & 36 & 24 & $7 \overline{6}$ & 16 \\
\hline 2. & Speaking Production & 116 & 4 & 46 & 66 & 8 & 66 & 42 & 12 & 84 & 20 \\
\hline 3. & Speaking Interaction & 116 & 8 & 38 & 70 & 8 & 70 & 38 & 17 & 84 & 18 \\
\hline 4. & Reading & 116 & 8 & 34 & 74 & 12 & 74 & 30 & 20 & 84 & 12 \\
\hline 5. & Writing & 116 & 8 & 52 & 56 & 8 & 60 & 48 & 16 & 86 & 14 \\
\hline
\end{tabular}

According to the results of a re-conducted questionnaire (after the second semester) to determine the level of explicit models using for language learning strategy instruction, it has been found that EG1 and EG2 students studying according to the "top-down" model have achieved significant progress in mastering the learning strategies. At the same time, EG3 and EG4 students demonstrated lower results in using learning strategies (Table 4).

Based on the calculation of the mean values of the input, intermediate, and output testing of educational achievements by types of communicative activity in four EGs, the mean learning coefficients have been calculated according to Bespalko's formula in four EGs. The mean learning coefficients of input, intermediate, and output testing of academic achievements are shown in table 5 . 
Table 4. Mean values of indicators of explicit models using for language learning strategy instruction

\begin{tabular}{|l|l|c|c|c|c|}
\hline \multicolumn{1}{|c|}{ Category } & EG1 & EG2 & EG3 & EG4 \\
\hline A. & Strategies for effective memorisation & 3.22 & 3.20 & 3.10 & 3.08 \\
\hline B. & Strategies for using all mental processes & 3.24 & 3.21 & 3.12 & 3.10 \\
\hline C. & Compensation strategies & 3.44 & 3.42 & 3.33 & 3.29 \\
\hline D. & Strategies for organising and evaluating learning & 3.21 & 3.19 & 3.16 & 3.17 \\
\hline E. & Emotion management strategies & 2.93 & 2.89 & 2.86 & 2.87 \\
\hline F. & Strategies for learning to cooperate with others & 3.39 & 3.38 & 3.29 & 3.30 \\
\hline & Mean value for all categories & 3.24 & 3.22 & 3.14 & 3.12 \\
\hline
\end{tabular}

Table 5. Learning coefficients of experimental groups according to Bespalko's formula

\begin{tabular}{|c|c|c|c|}
\hline \multirow{2}{*}{ Experimental Group } & \multicolumn{3}{|c|}{ Learning coefficient } \\
\cline { 2 - 4 } & Input Assessment & Intermediate Assessment & Output Assessment \\
\hline EG1 & 0.72 & 0.78 & 0.80 \\
\hline EG2 & 0.70 & 0.75 & 0.83 \\
\hline EG3 & 0.71 & 0.77 & 0.80 \\
\hline EG4 & 0.71 & 0.75 & 0.82 \\
\hline
\end{tabular}

The comparison calculation of Fisher angular transformation $\left(\varphi^{*}\right)$ is presented in table 6 .

Table 6. Comparison of input and output test results according to Fisher angular transformation $(\varphi *)$

\begin{tabular}{|c|c|c|c|c|c|c|c|c|c|c|c|c|}
\hline \multirow[t]{3}{*}{ Test } & \multicolumn{6}{|c|}{ EG1 $(N=28)$} & \multicolumn{6}{|c|}{ EG2 $(N=30)$} \\
\hline & \multicolumn{3}{|c|}{ Effect } & \multicolumn{3}{|c|}{ No Effect } & \multicolumn{3}{|c|}{ Effect } & \multicolumn{3}{|c|}{ No Effect } \\
\hline & $N$ & $\%$ & $\varphi^{*}$ & $N$ & $\%$ & $\varphi^{*}$ & $N$ & $\%$ & $\varphi^{*}$ & $N$ & $\%$ & $\varphi^{*}$ \\
\hline Input & 12 & 42.9 & 1.428 & 16 & 57.1 & 1.713 & 12 & 40 & 1.369 & 18 & 60 & 1.772 \\
\hline \multirow[t]{4}{*}{ Output } & 24 & 85.7 & 2.366 & 4 & 14.3 & 0.773 & 28 & 93 & 2.606 & 2 & 14 & 0.536 \\
\hline & \multicolumn{6}{|c|}{ EG3 (N=28) } & \multicolumn{6}{|c|}{ EG4 $(\mathbf{N}=30)$} \\
\hline & \multicolumn{3}{|c|}{ Effect } & \multicolumn{3}{|c|}{ No Effect } & \multicolumn{3}{|c|}{ Effect } & \multicolumn{3}{|c|}{ No Effect } \\
\hline & $N$ & $\%$ & $\varphi^{*}$ & $N$ & $\%$ & $\varphi^{*}$ & $N$ & $\%$ & $\varphi^{*}$ & $N$ & $\%$ & $\varphi^{*}$ \\
\hline Input & 12 & 42.9 & 1.428 & 16 & 57.1 & 1.713 & 12 & 40 & 1.369 & 18 & 60 & 1.772 \\
\hline Output & 24 & 85.7 & 2.366 & 4 & 14.3 & 0.773 & 26 & 86.7 & 2.395 & 4 & 13.3 & 0.747 \\
\hline
\end{tabular}

The calculated $\varphi^{*}{ }_{\text {emp. }}$ for each EG is the following: EG1 (6.566), EG2 (9.2775), EG3 (6.566), EG4 (7.695). The indicators are situated in the significance area that confirms the effectiveness of both variants of constructed method of explicit models using for language learning strategy instruction.

After conducting experimental training of professionally oriented English communication, students have been asked to answer the questionnaire, whether they are satisfied with the results of experimental learning. In general, the answer results have shown that all students are satisfied with the learning outcome and are ready to use the acquired knowledge and skills in further learning of professionally oriented English communication.

\section{Discussion}

Analysing individual indicators of 116 students at the beginning of experimental training, it should be noted that 22 freshmen have indicators of high-level mean values over 3.5, but only in eight of them, they are approaching $4(4.0 ; 4.1 ; 4.1 ; 4.4)$. Thus, these students usually use language strategies, but not systematically. At the same time, 24 students almost do not use the language strategies and the mean values of their answers are lower than 2.4. The analysis of the results of the conducted questionnaires indicates the expediency of conducting experimental training to increase the level of using language learning strategies in order to develop professionally oriented English communicative competence.

The results of the input test of academic achievements demonstrate a low level of competence in listening comprehension and speaking interaction was demonstrated by $60 \%$ of students, in speaking production $-57 \%$, in reading $-64 \%$, and in writing $-48 \%$ of students in experimental groups. At the same time, the results of the entrance test of academic achievements have shown that the composition of the 
participants of the experimental groups is homogeneous, as in all four groups students have got approximately the same points for communicative activities according to the determined levels.

The results of the input test of academic achievements, as well as the level using language learning strategies, allowed the implementation of experimental training of explicit models using for language learning strategies instruction of pre-service teachers in the process of professionally oriented English communication at university level.

As it can be seen from the results of the intermediate test to determine the level of academic achievements, the percentage of students with a low level of English proficiency decreased in all types of communication, namely: in listening comprehension is $31 \%$, in speaking production $-36 \%$, in speaking interaction $-33 \%$, in reading $-26 \%$, and in writing $-41 \%$.

According to the results of an intermediate questionnaire, it has been found that students of EG1 and EG2, who study according to the model "top-down", have achieved significant progress in mastering language learning strategies. At the same time, EG3 and EG4 students have shown lower results in mastering language learning strategies. Thus, it has been suggested that the level of mastery of language learning strategies may increase if cross-learning is conducted, which involves a change in methodology.

The mean values of indicators of explicit models using for language learning strategy instruction in the output testing significantly improved compared to the pre-experimental section, and in the categories "compensation strategies" (3.55), "strategies for organising and evaluating learning" (3.59), "strategies for learning to cooperate with others"(3.62) achieved the high level (3.50), which indicates the high efficiency of the proposed method of explicit models using for language learning strategy instruction of pre-service teachers in the process of professionally oriented English communication.

The analysis of the mean values for all categories has shown that the highest level of explicit models using for language learning strategy instruction has been found by students EG2 (3.53) and EG4 (3.51) (Table 5). Thus, the gained results confirm the correctness of the assumption about the expediency of combining explicit models "top-down" and "bottom-up" in the process of professionally oriented English communication.

The students' answers of the experimental groups to the open questions of the questionnaire on selfassessment of the implemented method of explicit models using for language learning strategy instruction in professionally oriented English communication have demonstrated that, in general, all pre-service teachers are satisfied with the results of experimental training, noted positive changes in their attitude towards learning. Also, they are ready to use the acquired knowledge and skills in further training in professionally oriented English communication.

The analysis of the results of the output testing shows the formation of professionally oriented English communicative competence at the level of B2 language proficiency, as well as a significant increase in knowledge, skills, and abilities of participants in explicit models using for language learning strategy instruction. Comparative results of the learning levels indicate an increase in all experimental groups, but the highest rate was found in EG2 (0.13), and the lowest - in EG1 (0.08). This fact confirms our assumption about the feasibility of combining the two variants of explicit models of language learning strategy instruction "top-down" and "bottom-up". The best indicators have been found in EG2, in which at the initial stage of training the option "top-down" was applied with a gradual transition to the option "bottom-up" at the advanced stage of training.

The accuracy of the obtained data was checked using a multifunctional statistical criterion - Fisher's angular transformation $\left(\varphi^{*}\right)$. It is found that the share of students who have achieved a sufficient level of learning coefficient 0.7 in EG1, EG2, EG3, EG4 according to the results of the output testing is higher than the results of the input testing, that confirms the overall effectiveness of experimental learning.

The effectiveness of explicit models using for language learning strategy instruction in the process of learning a foreign language is also confirmed by several other researches. For instance, the positive impact of learning strategies on the process of teaching speaking and writing has been noted in the works of Chamot (2005), Cohen (2006), Lee (2003), Zare (2012). The effectiveness of strategies in EFL of listening, reading, and vocabulary is proved in studies of Naeimi and Foo (2015), Shawer (2016), Taghinezhad et al. (2016), Thomson and Mehring (2016), Thomson and Rubin (1996), Urlaub (2012), and others.

Thus, we recommend applying the combination of explicit models for language learning strategy instruction in professionally oriented English communication. The implementation of both variants of explicit models helps to expand the repertoire of language learning strategies and their correct application, as well as improve students' learning autonomy for choice of the correct strategy. As a result, a high level of explicit models using for language learning strategy instruction of pre-service teachers influence on the development of their professionally oriented English communicative competence. 


\section{Limitations}

As the size of the sample is rather small $(n=116)$ and participants were from one Ukrainian university, the study results cannot be generalised as the sample selected cannot exemplify the entire population at large and participants do not present different universities. Rather, this study should be considered as an exploratory investigation that has the goal of identifying possible issues and trends for further research.

\section{Conclusions}

The analysis of the study shows the effectiveness of two variants of explicit models for language learning strategy instruction in professionally oriented English communication. At the same time, the combination of models used for EG2, namely, the use of the "top-down" model at the initial stage (1-2 semester) and the transition to the use of the "bottom-up" model at the advanced stage (3-4 semester), provided the best results in EG2. Replacing the "bottom-up" model with the "top-down" model in EG4 also contributes to a better result than in EG1 and EG3, in which students have studied according to the models during two stages of study.

To conclude, combining explicit models for language learning strategy instruction "top-down" and "bottom-up" contributes to more effective assimilation and expansion of the repertoire of learning and communication strategies for learning English. The effectiveness of the gradual shift from "top-down" to "bottom-up" in EG2 is explained by the fact that the low level of mastery of strategies demonstrated by firstyear students at the input testing has increased significantly after regular use of the "top-down" model, and involves teacher's active participation in modelling, explaining, encouraging and evaluating the proposed strategy, which contributes to the expansion of knowledge, skills, and abilities to use strategies and expands their repertoire. The shift to a "bottom-up" model at an advanced stage, when the level of students' learning English strategies has risen to average, contributes to increasing the level of student autonomy, as the "bottom-up" model involves student independence in analysing the learning situation, choosing learning or communicative strategy, self-assessment, but with the teacher's support in the analysis of results, feedback, and adjustment.

\section{References:}

Alhaysony, M. (2017). Language learning strategies use by Saudi EFL students: the effect of duration of English language study and gender. Theory and Practice in Language Studies, 7, 18-28. https://doi.org/10.17507/tpls.0701.03

Alshammari, S. (2020). EFL vocabulary learning strategies used by Saudi Arabia university students. Advanced Education, 16, 2838. https://doi.org/10.20535/2410-8286.202436

Anderson, N. (2005). L2 learning strategies. In E. Hinkel (Ed.), Handbook of research in second language teaching and learning. Lawrence Erlbaum Associates.

Bespalko, V. P. (1968). Opyt razrabotki i ispolzovaniya kriteriyev kachestva usvoyeniya znaniy [Experience in the development and use of criteria for the quality of knowledge assimilation]. Soviet Pedagogy, 4, 52-69.

Butler, D. L. (2002). Individualizing instruction in self-regulated learning. Theory into Practice, 41(2), 81-92. https://doi.org/10.1207/s15430421tip4102_4

Chamot, A. U., \& O'Malley, J. M. (1987). The cognitive academic language learning approach: A bridge to the mainstream. TESOL Quarterly, 21, 227-249. https://doi.org/10.2307/3586733

Chamot, A. U. (2005). The Cognitive Academic Language Learning Approach (CALLA): An update. In P.A. Richard-Amato \& M.A. Snow (Eds.), Academic success for English language learners: Strategies for K-12 mainstream teachers (pp.87-101). Longman.

Charoento, M. (2017). Individual learner differences and language learning strategies. Contemporary Education Researches Journal, 7, 57-72. https://doi.org/10.18844/cerj.v7i2.875

Cohen, A. (2006). Styles and Strategies-Based Instruction: A Teachers' Guide. Centre for Advanced Research on Language Acquisition, University of Minnesota.

Cohen, A. D. (2000). Strategies in Learning and Using a Second Language. Addison Wesley Longman Ltd.

Council of Europe. (2018). Common European Framework of reference for languages: learning, teaching, assessment-Companion volume with new descriptors. Council of Europe Publishing.

Dawadi, S. (2017). Language learning strategies profiles of EFL learners in Nepal. European Journal of Educational and Social Sciences, 2, 42-55. https://files.eric.ed.gov/fulltext/ED578188.pdf

Dmitrenko, N. Ye. (2000). Avtonomne navchannia profesiino oriientovanoho anhlomovnoho spilkuvannia maibutnikh uchyteliv matematyky: monohrafiia [Autonomous training of professionally oriented English communication of prospective teachers of Mathematics: monograph]. Vinnytsia, Ukraine: TOV Tvory.

Dmitrenko, N., Nikolaeva, S., Melnyk, L., \& Voloshyna, O. (2020). Autonomous ESP Learning of Prospective Teachers of Mathematics. Revista Romaneasca pentru Educatie Multidimensionala, 12(1), 86-104. https://doi.org/10.18662/rrem/201

Fisher, R. A. (2017). Statistical methods for research workers. Delhi: Kalpaz, New Delhi, India: distributed by Gyan Books Pvt. Ltd.

Green, J. M., \& Oxford, R. L. (1995). A closer look at learning strategies, L2 proficiency, and gender. TESOL Quarterly, 29(2), 261297. https://doi.org/10.2307/3587625

Grenfell, M., \& Harris, V. (1999). Modern languages and learning strategies: In theory and practice. Routledge.

Griffiths, C. (2003). Patterns of language learning strategy use. System, 31, 367-383. https://doi.org/10.1016\%2FS0346251X(03)00048-4

Griffiths, C. (2013). The strategy factor in successful language learning. Multilingual Matters. 
Griffiths, C., \& Incecay, G. (2016). New directions in language learning strategy research: engaging with the complexity of strategy use. In C. Gkonou, D. Tatzl, and S. Mercer (Eds.), New Directions in Language Learning Psychology (pp.25-38). Berlin: Springer. https://doi.org/10.1007/978-3-319-23491-5_3

Gu, P. Y. (2019). Approaches to Learning Strategy Instruction. In A. U. Chamot \& V. Harris (Eds.), Learning strategy instruction in the language classroom: Issues and implementation (pp.22-37). Multilingual Matters.

Habók, A., \& Magyar, A. (2018). The Effect of Language Learning Strategies on Proficiency, Attitudes and School Achievement. Frontiers in Psychology, 8, 1-8. https://doi.org/10.3389/fpsyg.2017.02358

Habók, A., Kong, Y., Ragchaa, J., \& Magyar, F. (2021). Cross-cultural differences in foreign language learning strategy preferences among Hungarian, Chinese and Mongolian University students. Heliyon, 7(3), e06505. https://doi.org/10.1016/j.heliyon.2021.e06505

Kline, R. B. (2015). Principles and Practice of Structural Equation Modeling. NY: Guilford Press.

Lai, Ying-Chun. (2013). Integrating vocabulary learning strategy instruction into EFL classrooms. Taiwan Journal of TESOL, 10(1), 37-76. Retrieved 12 October 2019 from http://www.tjtesol.org/index.php/current-issue/69-vol-10-no-1/385-integratingvocabulary-learning-strategy-instruction-into-efl-classrooms.html

Lee, K. (2003). The relationship of school year, sex and proficiency on the use of learning strategies in learning English. Asian EFL Journal, 5(4), 1-36. Retrieved 15 November 2018 from http://www.asian-efl-journal.com/sept_03_ok.pdf

Macaro, E. (2001). Learner strategies in second and foreign language classrooms. London Continium.

Naeimi, M., \& Foo, T. (2015). Vocabulary acquisition through direct and indirect learning strategies. English Language Teaching, 8 (10), 142-151. https://doi.org/10.5539\%2Felt.v8n10p142

O’Malley, J. M., \& Chamot, A. U. (1990). Learning strategies in second language acquisition. Cambridge University Press.

Oxford, R. L. (1990). Language learning strategies: What every teacher should know. Newbury House / Harper \& Row.

Oxford, R. L. (2016). Teaching and Researching Language Learning Strategies: Self-Regulation in Context. New York, NY: Routledge.

Oxford, R. L., \& Leaver, B. L. (1996). A synthesis of strategy instruction for language learners. In R. L. Oxford (Ed.), Language learning strategies around the world: Cross-cultural perspectives (pp.227-246). University of Hawaii Press.

Person, P. D., \& Dole, J. A. (1987). Explicit comprehension instruction: a review of research and a new conceptualization of learning. Elementary School Journal, 88(2), 151-165. https://doi.org/10.1086/461530

Pfenninger, S., \& Singleton, D. (2017). Beyond Age Effects in Instructional L2 Learning: Revisiting the Age Factor. Clevedon: Multilingual Matters. https://doi.org/10.21832/PFENNI7623

Platsidou, M., \& Kantaridou, Z. (2014). The role of attitudes and learning strategy use in predicting perceived competence in schoolaged foreign language learners. Journal of Language and Literature, 5(3), 253-260. https://doi.org/10.7813/j11.2014/5-3/43

Rahimi, M., Riazi, A., \& Saif, S. (2008). An investigation into the factors affecting the use of language learning strategies by Persian EFL learners. CJAL, 11(2), 31-60. Retrieved 5 June 2019 from https://journals.lib.unb.ca/index.php/CJAL/article/view/1991

Rao, Z. (2016). Language learning strategies and English proficiency: interpretations from information-processing theory. Language Learning Journal, 44, 90-106. https://doi.org/10.1080/09571736.2012.733886

Rubin, J., Chamot, A., Harris, V., \& Anderson, N. (2007). Intervening in the use of strategies. In A.D. Cohen \& E. Macaro (Eds.), Language learner strategies: Thirty years of research and practice (pp.141-160). Oxford: Oxford University Press.

Sarada, J. (2019). The use of '5a learning portfolio', a technique of learning strategies based on self-directed learning and metacognition to enhance English learning skills of Thai engineering students. PSAKU International Journal of Interdisciplinary Research, 8(1), 35-47.

Shawer, S. F. (2016). Four language skills performance, academic achievement, and learning strategy use in preservice teacher training programs. TESOL Journal, 7, 262-303. https://doi.org/10.1002/tesj.202

Taghinezhad, A., Azizi, M., Shahmohammadi, S., Kashanifar, F., \& Azadikhah, M. (2016). Comparing the effects of direct and indirect learning strategies on Iranian EFL learners' vocabulary learning. Journal of Applied Linguistics and Language Research, 3, 133-143. Retrieved 18 November 3018 from https://www.researchgate.net/publication/293719534

Thompson, I., \& Rubin, J. (1996). Can strategy instruction improve listening comprehension? Foreign Language Annals, 29(3), 33142. https://doi.org/10.1111\%2Fj.1944-9720.1996.tb01246.x

Thomson, R., \& Mehring, J. (2016). Better vocabulary study strategies for long term learning. University Humanities Review, 20, 133-141. Retrieved 18 November 2018 from https://www.semanticscholar.org/paper

Urlaub, P. (2012). Reading strategies and literature instruction: Teaching learners to generate questions to foster literary reading in the second language. System, 40, 296-304. http://doi.org/10.1016/j.system.2012.05.002

Zare, P. (2012). Language learning strategies among EFL/ESL learners: A review of literature. International Journal of Humanities and Social Science, 2(5), 162-169. Retrieved from http://www.ijhssnet.com/journals/Vol_2_No_5_March_2012/20.pdf 